Vestindo a pele do cordeiro: requalificação versus gentrificação no Recife Claudia Loureiro (1) e Luiz Amorin (2)

(1) arquiteta, Doutor em Arquitetura e Urbanismo, professor e pesquisador do Departamento de Arquitetura e Urbanismo da Universidade Federal de Pernambuco, Brasil; e-mail:

cloureiro@oi.com.br; (2) arquiteto, PhD UCL/University London, professor e pesquisador do Departamento de Arquitetura e Urbanismo da Universidade Federal de Pernambuco, Brasil; e-mail: amorin@ufpe.br 


\section{Vestindo a pele do cordeiro: requalificação versus gentrificação no Recife}

Resumo

Nas últimas décadas, os centros históricos das grandes cidades latino-americanas vêm sofrendo um lento, mas destrutivo processo de redução de investimentos. O cenário de abandono e substituição de funções qualificadas por serviços de baixa especialização é evidente, bem como os seus efeitos na imagem das cidades. O poder público vem investindo em projetos e políticas de requalificação destas áreas centrais como uma estratégia de manutenção de sua identidade física, mas também como forma de participar do mercado turístico internacional, opção adequada para motivar o retorno de investimentos privados. No entanto, a grande expectativa está no envolvimento do capital privado imobiliário para investir nas áreas centrais e no conseqüente reaquecimento da economia local.

Este artigo analisa recente empreendimento imobiliário na cidade do Recife que pretende, através da oferta de novas moradias para população de classe média alta, promover uma requalificação do centro histórico da cidade. A área foi elevada pela municipalidade à condição de sítio histórico urbano em finais da década de 1970, por conter um grande número de edificações religiosas do século XVIII e manter uma ambiência urbana setecentista. O empreendimento é composto por duas torres com 40 pavimentos, cujas características arquitetônicas comprometem a integridade da área tombada, particularmente no que se refere aos aspectos de escala e relação entre espaços público e privado. Pretende-se discutir os impactos do empreendimento sobre o sítio histórico, demonstrar que seus efeitos na requalificação da área serão mínimos e sugerir empreendimentos mais adequados para promover uma requalificação do centro histórico.

\section{Abstract}

The historic cores of the large Latin-American cities have been suffering, from the past few decades, a slow, but destructive process of desinvestment. The scenery is of abandonment and substitution of qualified services for non-qualified ones, with evident effect on the image of these cities. Municipalities have been investing on rehabilitation policies and projects of the central areas as a strategy to sustain their identities, but also to take part on the global tourist market as a way to promote the return of private investors. However, the main expectance is on the return of the property market to the central areas to improve the local economy.

This article discusses a recent development in Recife, Brazil, that intends to rehabilitate the historic city centre by offering new housing to the high middle class. The area was listed in late 1970s for its XVIII century ambiance and number and quality of its religious buildings. The development in question is composed of two high-rise towers with 40 floors, which architectural properties jeopardize the integrity of the listed site, particularly with regards to the scale and the relationship between public and private spaces. It is of interest to discuss the impacts of the development on the historic site, to demonstrate that the effects on its rehabilitation will be irrelevant and to suggest adequate developments to best promote the rehabilitation process. 


\section{Recife e suas torres gêmeas...}

No ano de 2005, com grande alardeio, uma tradicional empresa no ramo de construção de prédios residenciais de luxo (e altos), lançou, ocupando três páginas do primeiro caderno do mais antigo jornal da América Latina, o Diario de Pernambuco (o que seria equivalente ao horário nobre na TV), seu mais recente e ousado empreendimento: os edifícios Píer Duarte Coelho e Píer Maurício de Nassau. Os edifícios estão sendo construídos no Cais de Santa Rita, às margens da Bacia do Pina, no Bairro de São José, dos mais antigos da cidade do Recife (ver figuras 1 e 2).

A denominação dos edifícios, de forte apelo histórico, evocando heróis da história pernambucana (ainda que Maurício de Nassau, governador do Brasil holandês no século XVII, tenha sido 'recuperado' como herói apenas recentemente), foi escolhido, segundo informações do site da empresa $^{1}$, por meio de uma enquete, traduzindo tendência atual do gosto pelas coisas do passado, que parecem garantir, ou recuperar, uma certa identidade cultural, ainda que, em certas circunstâncias, este passado tenha que ser inventado. Esta tendência responde às demandas contemporâneas que associam a diversão e o lazer, garantido pelo consumo de bens patrimoniais, ao status e à tradição impregnadas nestes bens ${ }^{2}$.
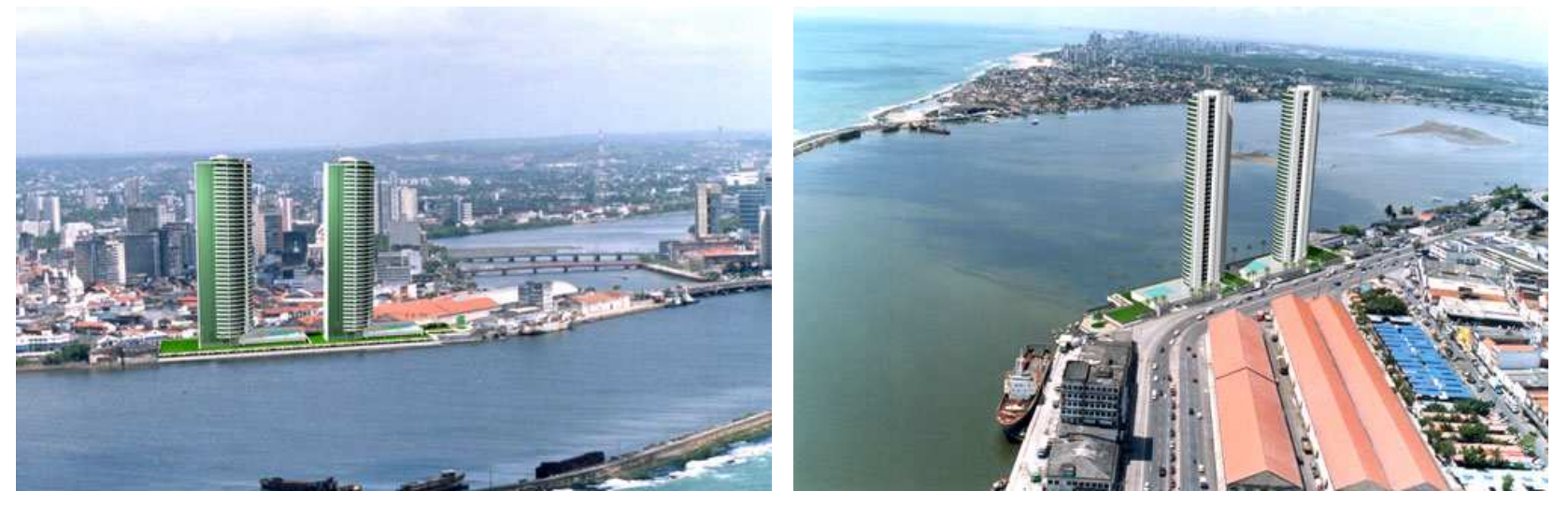

Figura 1 e 2 - perspectiva promocional (Fonte: www.mouradubeux.com.br)

O texto promocional de lançamento do empreendimento enaltece a sintonia da empresa com os "melhores sonhos do recifense" e o apresenta como uma "nova e deslumbrante alternativa de moradia ... que certamente contribuirá para tornar o Recife mais bonito e mais moderno."3 As frases-chave da peça publicitária ${ }^{4}$ destacam o $\mathrm{V}$ da palavra-chave 'viver'; qualquer semelhança com o V da vitória não é mera coincidência. Do primeiro anúncio do empreendimento, em 2003, até o presente lançamento, o projeto passou por várias instâncias de discussão para sua aprovação final, com modificações em relação à proposta original, que previa três torres de 27 pavimentos, com dois apartamentos de $230 \mathrm{~m}^{2}$ por andar (Souza, Amorim e Loureiro, 2004). Depois de longa discussão, uma proposta alternativa foi acordada pelos componentes da CDU -

\footnotetext{
${ }^{1}$ www.mouradubeux.com.br.

${ }_{2}^{2}$ A este respeito, ver Choay, 2001.

${ }^{3}$ Destaque nosso.

4 "Viva uma avançada concepção arquitetônica"; "Viva um deslumbrante visual"; "Viva uma agradável área de lazer"; "Viva uma inovadora localização"
} 
Conselho de Desenvolvimento Urbano ${ }^{5}$, que resultou no projeto aprovado, composto de duas torres com 40 pavimentos, com um apartamento de $247 \mathrm{~m}^{2}$ de área privativa por andar.

A empresa aposta na gentrificação da área, ao entender o empreendimento como uma âncora para a urbanização do centro, atraindo pessoas formadoras de opinião, vale dizer, jovens profissionais urbanos, que valorizem e divulguem a área (cf. Souza, Amorim e Loureiro, 2004). De fato, este entendimento parece se difundir no seio da sociedade pernambucana, a julgar por recentes matérias jornalísticas que apontam tradicionais bairros do centro como alternativa para moradia, já atraindo novos moradores, sendo todos de renda familiar bem inferior àquela à qual o empreendimento no Cais de Santa Rita se destina (Vasconcelos, 2005). Esta possível demanda para moradia no centro parece ser confirmada a partir do primeiro empreendimento imobiliário com fins habitacionais em décadas foi desenvolvido no bojo do projeto Morar no Centro, uma parceria entre a prefeitura do município, Ministério das Cidades e CEF - Caixa Econômica Federal, banco oficial responsável pelo financiamento de projetos sociais. O empreendimento consistiu na requalificação de edifício de oito pavimentos que se encontrava em desuso (figura 3). A oferta de 56 apartamentos do edifício requalificado teve uma grande procura, o que parece sugerir um prenúncio de uma espécie de corrida para o centro por parte da população de menor poder aquisitivo, com rendimentos familiares equivalentes a seis salários mínimos.

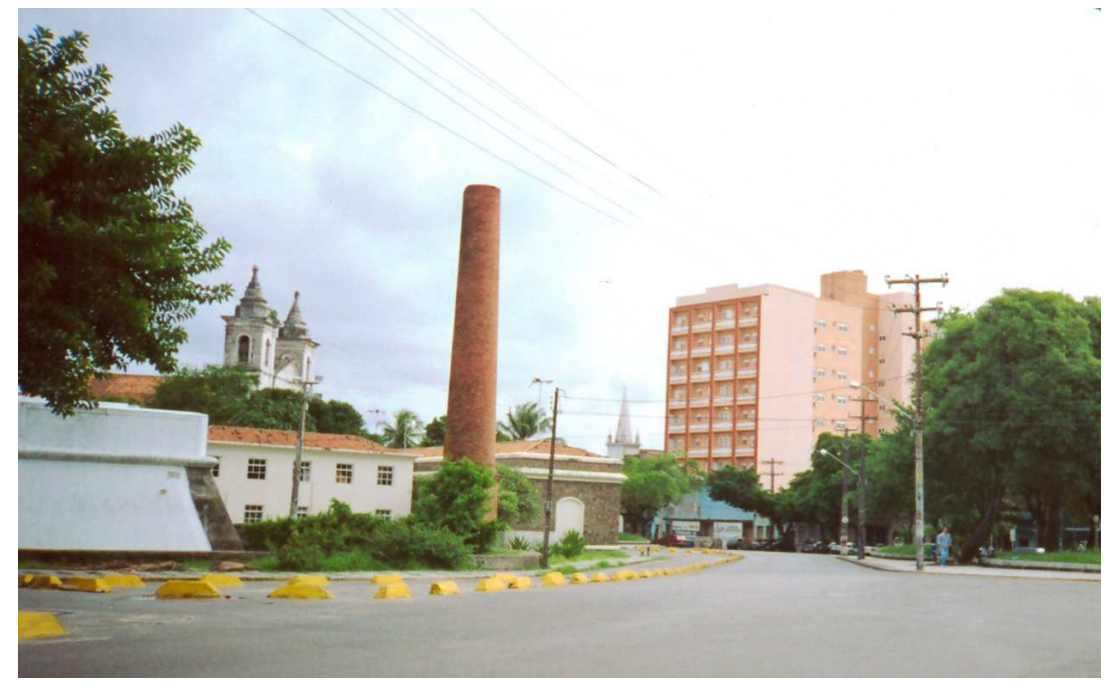

Figura 3. Edifício São José, reabilitado com recursos do PAR (foto: Claudia Loureiro, 2004)

Estes dois empreendimentos, as torres no Cais de Santa Rita e o Ed. São José, ilustram bem o interesse da municipalidade em instituir um interesse imobiliário nos bairros centrais da cidade, visando reverter o processo de empobrecimento. No entanto, se o segundo observa os critérios de melhoria de imóvel existente sem alterar seus padrões urbanísticos (apesar de sua planta interna ter sido remodelada para aumentar o número de apartamentos e se adequar ao Programa de Arrendamento Residencial - PAR, definido pela CEF), o primeiro parte do pressuposto da máxima

\footnotetext{
${ }^{5}$ O Conselho é formado por representantes da Prefeitura da cidade e de representantes de diversas entidades da sociedade civil, incluindo a entidade representante dos empreendedores imobiliários e a dos arquitetos e urbanistas, e tem a função de definir diretrizes e deliberar sobre questões urbanísticas excepcionais e sobre os instrumentos de planejamento da cidade, como o plano diretor.
} 
rentabilidade como forma de viabilizar o empreendimento imobiliário, em detrimento das condições urbanísticas locais.

Assim, o primeiro se classifica como especulação imobiliária, e adota suas regras, sendo que, neste caso, os lucros são máximos, dado que, uma vez que a área de implantação se caracteriza como uma espécie de brownfield, ainda não havia sofrido valorização fundiária expressiva. O segundo, por sua vez, tem como foco a requalificação do bairro, e, por conseguinte, adota as regras de preservação da ambiência, ainda que a edificação em questão não apresente valores excepcionais, porém, o perfil urbano pré-existente é preservado.

\section{O sítio histórico de São José}

Os dois empreendimentos descritos estão localizados em um mesmo bairro histórico, sendo que o Ed. São José é interior aos limites do Sítio Histórico, e as torres historiadas pela denominação, estão localizadas 'fora-de-portas', distando destes limites não mais que 100 metros. Por esta razão, não estão sujeitas às restrições do sítio.

O Bairro de São José, área histórica adjacente ao cais, é um dos mais antigos arruamentos do Recife, cuja ocupação remonta ao século XVII, como o bairro habitacional do plano de Pieter Post no período de ocupação holandesa. Sua configuração atual, no entanto, se deve à consolidação daquela faixa após a reconquista lusitana, formando, talvez, o conjunto barroco de maior importância do estado de Pernambuco. O cenário urbano é composto, na sua maioria, por construções geminadas, de testada estreita, e de no máximo 3 pavimentos, segundo tipo arquitetônico local conhecido por sobrado. Os espaços públicos seguem a tradição lusitana de construir nas suas colônias, com vias irregulares de pequena largura articulando adros e pátios, foco de cerimônias religiosas e seculares (Figuras 4 e 5).

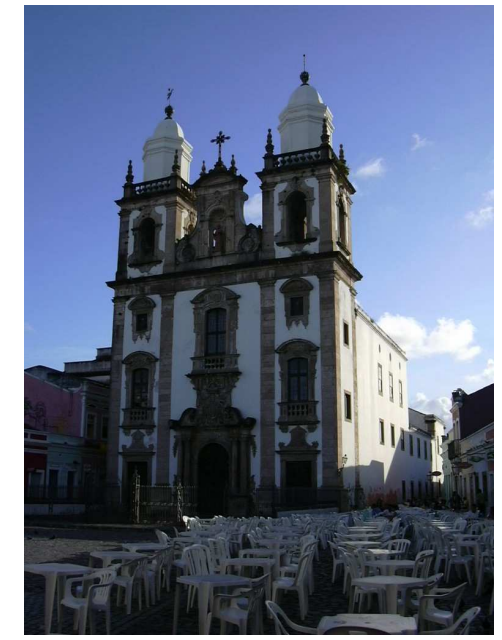

Figura 4. Igreja São Pedro dos Clérigos, Recife, 2003 (Foto: Cristiana Griz)

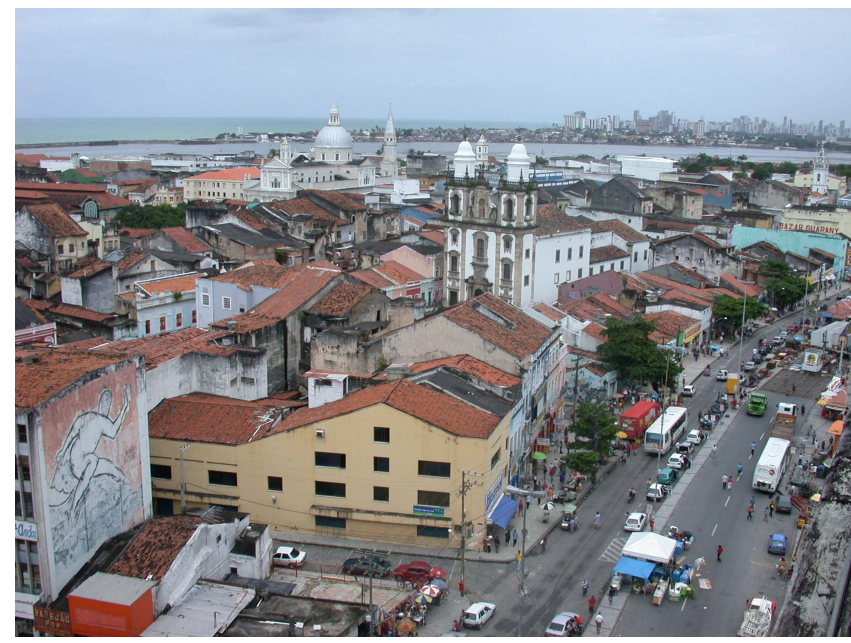

Figura 5. Vista do Bairro de São José, 2004 - ao fundo, área onde está sendo construído o empreendimento (Foto: Luiz Amorim)

Josué de Castro bem descreve a ambiência do lugar,

... [São José] tem um aspecto quase suburbano, inteiramente diferente, com suas ruas atropeladas, enoveladas, com suas casas em promiscuidade, com seus pequenos 
funcionários públicos de vida apertada para parecer classe média, morando em casinhas de porta e janela, e com seu comércio de artigos baratos, com preços apregoados nas portas por árabes e turcos. Ruas estreitas, becos, travessas. Confusão. O aperto da rua Direita e da rua do Livramento. Cenário oriental. Mercado de miudezas e de chitas vistosas pregadas nas fachadas das casas de nomes ingenuamente deliciosos: "A Simpatia", "A Magnólia”, etc. (cf. Maior e Silva, 1992: 256).

O bairro, segundo dados do último censo, de $2000^{6}$, possui cerca de 8600 habitantes, com uma renda média familiar de $R \$ 314$ (cerca de $U \$ 120$, a preços de 2005). Tal qual todos os bairros que formam o centro expandido de Recife, houve um decréscimo de população na última década do século $X X$.

Ainda que durante a ocupação holandesa do século XVII tenha surgido como área habitacional da Cidade Maurícia, parece não ter sido a destinação exclusiva do bairro, tendo se consolidado ao longo do tempo como zona comercial varejista, de intensa atividade urbana. Hoje, sua dinamicidade é dada por um intenso comércio de características populares, que garantem movimento durante o dia. Do ponto de vista de sua estrutura física, o bairro tem uma quantidade significativa de imóveis vazios ou ocupados com atividades pouco nobres, como estacionamento de veículos e depósitos.

O Cais de Santa Rita, localizado no waterfront da Bacia do Pina e nas bordas do sítio histórico, é uma área conquistada às águas, fruto de aterro realizado na primeira metade do século XX, com o objetivo de gerar área para atender à expansão das atividades portuárias, com a localização de armazéns e comércio atacadista. A redução das atividades portuárias no final do século passado e a transferência dos investimentos públicos e privados para novas centralidades urbanas, contribuíram para o cenário atual de transferência de capital do mercado imobiliário na zona central da cidade. O empreendimento para o Cais de Santa Rita é visto pelos seus idealizadores como um caminho para reverter este quadro de estagnação e trazer uma nova população para a área. $\mathrm{Na}$ realidade, o empreendimento se insere em uma estratégia de mercado adotada pela empresa baseada na identificação de demandas reprimidas por parte de uma clientela diferenciada e a oferta de produtos que a satisfaça. As torres gêmeas recifenses foram desenhadas com este propósito: oferece uma situação geográfica ímpar, como vista definitiva (jargão publicitário para caracterizar os edifícios que não terão a paisagem bloqueada por futuros empreendimentos em terrenos vizinhos) para uma população que detém recursos financeiros para acessar o seu imóvel tanto pela terra, quanto pela água, quanto pelo ar; cujas redes de socialização são transpacialmente constituídas, ou seja, não se dão na sua vizinhança imediata, e cujo território circundante é apenas panorâmico, ou seja, a zona urbana decadente é passagem e paisagem, e não permanência. Assim, os futuros moradores irão introduzir um padrão de moradia distinto do padrão existente no bairro: irão transferir modos de vida que independem da sua

\footnotetext{
${ }^{6}$ Dados do IBGE - Instituto Brasileiro de Geografia e Estatística.
} 
localização geográfica.

O projeto aprovado, com apartamentos com quatro suítes, sala para três ambientes e mais uma cobertura duplex, encimada, naturalmente, por um heliporto privado, prevê área de lazer para atender a todas as necessidades dos futuros moradores - corpo, mente, e espírito: área para ginástica, para festas, para gastronomia e esportes, inclusive esportes náuticos. Pode-se dizer que a empresa responsável pelo empreendimento usa as estratégias que vêm garantindo seu sucesso no mercado imobiliário recifense, da formulação do programa até sua denominação, e que dão base à constituição de um sonho vivo de morar (Amorim e Loureiro, 2003; Loureiro e Amorim, 2002; Loureiro e Amorim, 2005; Borba, Loureiro e Amorim, 2002; Nascimento et al., 2004; Souza, Amorim e Loureiro, 2004). A particularidade neste caso está, no entanto, em dois aspectos fundamentais do projeto: a) a aplicação destas estratégias em zona urbana degradada, b) oferta de edifício de apartamentos em zona urbana nunca dantes habitada, c) a agregação de valor à empresa como agente de renovação urbana, mesmo que não se constitua de fato, como discutido adiante.

\section{O debate público: argumentos e contra-argumentos - torres e não-torres}

O lançamento bombástico do empreendimento das torres logo começou a surtir seus efeitos na cidade, causando incomodo em algumas pessoas cidadãos e estudiosos e ensejando um debate travado pela mídia e pela Internet. Mensagens eletrônicas contra o projeto começaram a circular logo após a publicação da propaganda, em 10/03/2005. A iniciativa contra o empreendimento mais contundente, contudo, partiu do Ministério Público Federal - MPF ${ }^{7}$, que ingressou com uma ação na Justiça Federal contra o empreendedor, o município e o Instituto do Patrimônio Histórico e Artístico Nacional - IPHAN. O argumento do MPF é o da proteção dos sítios históricos do centro da cidade, argumento este que não parece ter sensibilizado o IPHAN que se exime de qualquer responsabilidade de análise do projeto dado que este se encontra "fora do limite de proteção dos bens tombados ..." (JC, 2005a). Na verdade, o empreendimento "margeia" estes limites, no entanto, seu impacto na manutenção das características do sítio é significativo. A ação do MFP, no entanto, não foi acatada pelo Tribunal Regional Federal - TRF. O presidente do tribunal considerou a obra importante porque ela recuperaria, na opinião do desembargador, a paisagem urbana degradada e que esta seria uma intervenção capaz de propiciar outras realizações de revitalização do centro histórico, a exemplo de projetos turísticos (Diario de Pernambuco, 2005). Opinião que denota um conhecimento profundo do campo do arquiteto e urbanista, profissional capacitado para avaliar os impactos de uma intervenção deste tipo, o que certamente não é o caso do jurista.

\footnotetext{
${ }^{7}$ O Ministério Público é uma instituição ligada à Procuradoria Geral da República e tem por atribuição a defesa da ordem jurídica, do regime democrático e dos interesses sociais e individuais indisponíveis e de fiscalização e salvaguarda dos princípios e interesses fundamentais da sociedade (Constituição Federal, art. 127).

${ }^{8}$ Estes limites referem-se ao polígono do Sítio Historio do Bairro de São José, que compreende dois setores - proteção rigorosa e proteção ambiental, conforme definidos no PPSH - Plano de Preservação de Sítios Históricos, de 1979. No setor de proteção rigorosa, demolições e mudanças de traçado são proibidas, assim como o remembramento de lotes. Com relação à edificação, preserva-se o alinhamento, o gabarito, a forma da coberta e materiais, entre outros elementos. No setor de proteção ambiental, que tem por finalidade estabelecer uma zona de transição, transformações e novas construções são admitidas, com controle do gabarito.
} 
É animador o fato de que um empreendimento imobiliário tenha instigado uma discussão sobre a cidade como pouco se viu na história recente do Recife. Discutir a cidade é sempre saudável e todos ganham com o debate. Em poucas semanas, de forma reativa à ação do MPF, ao menos três artigos foram publicados em jornal de grande circulação, todos ávidos na defesa do que entendem por ousadia e pioneirismo de empreendedores que, com altruísmo, pensam em deixar sua contribuição positiva para a cidade. Desanimador é o fato de que estes artigos se utilizem, na defesa do empreendimento, da tática de desqualificar profissionalmente aqueles que questionam o seu valor e conseqüências para a vida urbana. Não chegam, portanto, a defender uma tese. Com esta estratégia, os autores dos três artigos, pretensamente falando ex cathedra, não logram discutir aspectos importantes para a cidade. Em todos o recurso a uma 'autoridade' externa, atual ou do passado, é recorrente para apoiar o que se defende.

O primeiro artigo (Ferraz, 2005) defende com vigor o empreendimento das torres no Cais de Sta Rita, recorrendo à autoridade histórica de figuras eminentes na cidade e acusando aqueles que são contra de valer-se de um 'processo de infantilismo intelectual' (sic). O artigo se inicia chamando atenção para repetição de erros históricos em um 'cenário de farsa' (sic), no qual, segundo a autora, "reedita-se ... o discurso contra Duarte Coelho ..., Maurício de Nassau ..., Conde da Boa Vista ... e Sérgio Loreto ...." ${ }^{9}$ De fato, a história se repete, para o bem ou para 0 mal. E isto não quer dizer que fatos históricos ofereçam sempre bons exemplos. No caso do Bairro de São José, a história se repete agora por acréscimo e não por supressão, como na década de 1970, quando o então prefeito da cidade, baseado nos mesmos argumentos da autora, sacrificou parte substancial do histórico sítio de São José e do patrimônio histórico, para, em nome do progresso, abrir a tão 'monumental' quanto inútil Avenida Dantas Barreto (ver figura 6). E a história também se encarrega de mostrar o quanto de acertos e de erros estão contidos nas ações de planejadores e empreendedores 'pioneiros'. Basta olhar casos semelhantes alhures, casos estes que, quase sempre, servem de inspiração e justificativa para tais pioneiros empreendimentos.

Um segundo argumento utilizado no artigo diz respeito à inclusão social - seriam "150 felizardas famílias pioneiras" que se somariam aos moradores que resistiram à degradação do bairro. Somar-se? Como? O argumento da inclusão social vale para muita coisa e tem sido bastante utilizado ultimamente - cabe perguntar de que 'social' estamos falando? Não se têm notícias de que residentes da alta classe média se somem a camadas mais populares, como a que reside no bairro. Muito pelo contrário, a convivência é sempre conflituosa. Como, então, um empreendimento deste porte, destinado a tão privilegiados moradores, cria mecanismos que garantam a permanência da população atual e até incentive a vinda de novos moradores de todas as classes?

A própria noção de revitalização (grifo nosso) já é polêmica - o termo, carregado de preconceito, pode ser traduzido por 'outra vida, já que a existente não serve...'. O termo quer dizer 'voltar à

\footnotetext{
${ }^{9}$ Gestores públicos com importante papel na configuração dos espaços públicos em Pernambuco.
} 
vida', supondo-se que algo está morto. O Bairro de São José não morreu - pouca gente lá habita, é certo, mas o bairro tem um dinamismo próprio, com um intenso comércio popular. Via de regra, processos caracterizados por gentrificação, como é o caso do empreendimento em tela, resultam em exclusão social. Claro está que a ninguém interessa a perpetuação da degradação da área, o que significaria sua morte certa, mas, como afirma Holanda, processos de gentrificação, por outro lado, não são garantia de preservação (Holanda, 2005 - mensagem eletrônica). A equação é complexa, mas tem solução.

Também o argumento de que os moradores das torres possibilitariam a 'revitalização' da área é utilizado no segundo artigo (Laprovitera, 2005). O autor defende que o conceito de preservação deva ser aquele que entende a cidade como "a arquitetura e a cidade como entidade viva (sic), centrada nos usuários que animam seus espaços e ruas" e não a visão, que segundo ele estaria subjacente às posturas reativas, que trata a cidade como algo intocável (Laprovitera, 2005). Sem querer entrar no debate Ruskin x Viollet-Le-Duc, bastante interessante, por sinal, não há nas ditas posturas reativas, até onde se sabe, nada que corrobore esta assertiva. A questão da salvaguarda do patrimônio não é de forma alguma assim polarizada. Que o Bairro de São José, Santo Antônio, do Recife e da Boa Vista ${ }^{10}$ necessitam de ações urgentes para sua salvaguarda não se discute; o que se discute são as formas de intervenção.

O entendimento da cidade como entidade viva se materializaria, segundo o autor, com os ganhos advindos com a fixação de 150 famílias no local. Alguém imagina os futuros moradores, todos de classe média alta, animando os espaços do Bairro de São José, a não ser no Carnaval, durante o desfile do Galo da Madrugada ${ }^{11}$ ? Como referido acima, os vínculos da nova classe média são transpaciais em essência - eles se baseiam em relações que não dependem do lugar como estrutura física para suporte de suas redes de socialização, o que não acontece com os moradores atuais do bairro. Em assim sendo, a nova classe média tem a tendência de se proteger das patologias sociais que a rodeia, criando muros e sistemas que a isole destas e de outras patologias. Assim sendo, que ganhos seriam estes?

O autor também vê na ação do MPF uma ameaça à democracia, e defende a autoridade soberana das instituições que têm assento no CDU de decidir sobre a cidade, excluindo todo e qualquer direito dos demais cidadãos de discutir sua cidade. Ainda bem que a Constituição da República Federativa do Brasil, no capítulo dos direitos e garantias fundamentais, contradiz o autor e garante que "qualquer cidadão é parte legítima para propor ação popular que vise a anular ato lesivo ao patrimônio público ou de entidade de que o Estado participe, à moralidade administrativa, ao meio ambiente e ao patrimônio histórico e cultural ...." ${ }^{12}$ E o MPF também tem a atribuição de salvaguardar os interesses da sociedade.

\footnotetext{
${ }^{10}$ Bairros que formam o centro histórico da cidade.

11 Trata-se de bloco carnavalesco surgido no bairro na década de 1970 e que hoje, em dias dos festejos de Momo, reúne mais de um milhão de pessoas (de todas as classes) nas ruas do centro da cidade.

12 Destaque nosso.
} 
Por fim, argumentos relacionados à estética e arquitetura são também levantados, recorrendo a diferentes autoridades para Ihes dar credibilidade. Ainda na linha da história da cidade, Ferraz (2005) pretende ancorar sua defesa das torres numa dita tradição da cidade, recorrendo ao Palácio das Torres, residência de Nassau, no século XVII, desaparecido há quatro séculos e do qual resta apenas uma memória iconográfica. A questão não é de torre, ou não de torre - se a residência de Nassau tinha torres (duas), as igrejas barrocas do bairro também e elas estão ainda lá e fazem parte do processo de constituição do traçado do bairro e do senso de identidade histórica da cidade. Aliás, o argumento é de todo desprovido de fundamento, pois as torres as quais a autora se refere, são partes constituintes de um conjunto arquitetônico edificado, e não uma edificação que, por suas propriedades geométricas, ganha a alcunha de torre de apartamentos. De toda a forma, as torres barrocas tendem a perder sua imponência com as novas torres, não pelo fato de serem estes edifícios com 40 andares, ou seja, cerca de 120 metros de altura, mas sim tendem a perder seu valor artístico pela diferença de escala. A questão da escala não é mero diletantismo, e sim é um dos inúmeros aspectos tratados nas cartas patrimoniais que discutem as estratégias de salvaguarda do patrimônio histórico e cultural - e com isto não se está defendendo o 'congelamento' das estruturas, mas o respeito. Além disso, a construção das torres se fará em um dos únicos pontos da cidade cuja visão do panorama setecentista permanece quase inalterado. O impacto na paisagem urbana é de tal ordem que as torres das igrejas do Bairro de São José deixarão de ser marcos referenciais de uma cidade que se pretende ser reconhecida como patrimônio da humanidade ${ }^{13}$.

No terceiro artigo (Cruz, 2005), o autor desenvolve dois argumentos: um arquitetônico e o outro, urbano. Ressaltando a singular arquitetura do empreendimento, louva o talento "dos arquitetos da terra" (sic). Ora, novamente o que está em questão não é o talento dos autores do projeto, incontestável, ou a qualidade da arquitetura do empreendimento. O que se discute é qualidade de vida urbana. O que fica evidente é que a questão da qualidade de vida urbana é freqüentemente engolida por argumentos que associam criatividade à "acrobacias tecnológicas e formais" (Marques, 2005 - mensagem eletrônica), ou por argumentos simplistas, como o do IPHAN quando levanta a questão dos limites de proteção dos bens tombados, que muitas vezes representam tecnicalidades sem muita profundidade (o terreno do empreendimento localiza-se a menos de 100 metros deste limite). Cruz vê provincianismo na voz daqueles que ousaram contestar a "opinião de renomados especialistas" (sic) - como se, entre estas vozes, também não se encontrem renomados especialistas! Focando o debate em questões menos pessoais, o autor vê na polêmica um horizonte sombrio de restrições a um dos projetos, segundo ele, mais esperados pela cidade, que seria o da operação urbana consorciada no setor do Bairro de São José, entre a Rua Imperial e o Cais José Estelita. Esta operação urbana funcionaria como uma "forma de resgate para 0 bairro e para a sua centralidade" (Cruz, 2005). O autor lembra o papel das operações urbanas, instrumento concebido no Estatuto da Cidade, de "alcançar transformações urbanísticas

\footnotetext{
${ }^{13}$ A municipalidade apresentou, em 2004, proposta de reconhecimento do seu núcleo histórico como patrimônio da humanidade.
} 
estruturais, melhorias sociais e valorização ambiental' (cf. Cruz, 2005). Do ponto de vista da arquitetura, o autor compara as torres recifenses a obras emblemáticas alhures. Diz o autor que as "vozes precipitadas e intolerantes" (sic) daqueles que ousaram discutir o empreendimento seriam "inconseqüentes como instrumento de persuasão de idéias", e, se ecoadas em outras plagas, "a humanidade estaria privada da pirâmide do Louvre; do Arco Quadrado de La Defense; da Biblioteca Nacional; e até, provavelmente, da própria torre Eiffel'. A comparação foi, no mínimo, infeliz, posto que os impactos destas obras não são comparáveis nem entre si e nem ao caso do Recife.

Outros argumentos foram ainda levantados, em debates livres e conversas informais pela cidade, além do argumento da modernidade, ressaltado na propaganda (e que está associado a progresso, ou ousadia, tecnológica $)^{14}$. Um dos mais fortes contrapõe o argumento demográfico - a necessidade de crescer a oferta de unidades habitacionais para abrigar uma crescente população, a um argumento geográfico - a exígua área do município. Aí dois equívocos se escondem. $\mathrm{O}$ primeiro relaciona-se aos aspectos demográficos: a população do município do Recife não está crescendo como se pensa - o que cresce é a população da região metropolitana, da qual o município é 1/14 parte. Pode-se, pois, contra-argumentar questionando para quem estão sendo direcionadas as unidades de luxo ofertadas no mercado. Notícias nos jornais dão conta do interesse e da efetiva conclusão de negócios por parte de estrangeiros, ainda que em pequeno número, não somente em Pernambuco, mas em outros estados do Nordeste (JC, 2005b). Com o euro em alta, é fácil perceber que a tendência observada não é indicativa de uma crescente migração, mas de puro investimento especulativo ou para uso sazonal - o verão Nordestino é um grande atrativo turístico. Esta é uma clientela com grande potencial de investimento. Se os números relativos aos negócios de estrangeiros ainda são pequenos, que outros tipos de especuladores estariam investindo no mercado imobiliário em Recife? ...

O segundo equívoco diz respeito ao tamanho do município, sabidamente pequeno e cercado de morros. Este é um argumento sofismático - não se pode pensar Recife como Recife - ou melhor, Recife não é Recife, é a região metropolitana, mesmo antes desta ser instituída por lei, na década de 1970. Pode-se argumentar que não se pode considerar Abreu e Lima ou Igarassú ${ }^{15}$ como parte do Recife; ainda assim, a conta tem que levar em consideração ao menos mais três municípios adjacentes: Jaboatão dos Guararapes, Olinda e Camaragibe. Por outro lado, recentes investimentos em obras viárias trouxeram para mais 'próximo' municípios distantes, como é o caso de Gravatá, a cerca de $80 \mathrm{Km}$. Assim, Recife tem para onde crescer.

O argumento apóia-se no que Smith (1996) chamou de constituição de novas fronteiras urbanas, que se caracteriza não por expansão de fronteiras, mas sim por diferenciação interna de áreas ocupadas, freqüentemente envolvendo processos de gentrificação, como é o caso. De fato, a área se situa numa fronteira de gentrificação, como definido por Smith (1996). A linha de fronteira seria

\footnotetext{
${ }_{15}^{14}$ Recife se tornaria uma cidade equiparada, do ponto de vista tecnológico, às grandes metrópoles do mundo.

${ }^{15}$ Municípios distantes, respectivamente, 20 e $26 \mathrm{Km}$ da sede da região metropolitana e que não lhes são adjacentes.
} 
exatamente os limites do sítio histórico, referidos pelo IPHAN, ao eximir-se de qualquer ingerência sobre o projeto. Uma fronteira de gentrificação representa a linha que divide áreas de degradadas de áreas de reinvestimento, envolvendo retorno de capital em estruturas que experimentaram transferência de capital imobiliário anteriormente. Assim concebida, a fronteira representa a linha histórica e geográfica avançada do projeto urbano de reestruturação e gentrificação (Smith 1996: 190). Este é o caso do Cais de Santa Rita. As formas de reinvestimento podem variar substancialmente, podendo envolver a reabilitação do estoque edificado, o investimento público em infra-estrutura ou o investimento privado em novas construções. No caso, optou-se pela última forma, sem a contrapartida das outras duas, e sem observar as peculiaridades paisagísticas, urbanísticas e históricas.

\section{Por um reinvestimento plural}

O caso das torres gêmeas de São José evoca importantes conflitos no âmbito do planejamento, da gestão e da economia urbanos. Também ressalta a necessidade de rever os conceitos de preservação de sítios históricos e de estabelecer uma política de restauração que observe o capital privado como uma fonte de financiamento e parceira na própria formulação de planos de requalificação urbana. Como preconiza o IPHAN, uma tal política "deve buscar,antes de tudo, um equilíbrio favorável à sociedade entre o valor econômico e o valor cultural dos sítios tombados" (IPHAN, 2003, p. 7).

A divulgação do empreendimento e as discussões públicas que se seguiram tiveram sempre como foco de interesse a renovação urbana do Bairro de São José e a necessidade de torná-lo objeto de interesse imobiliário, no entanto, os argumentos apresentados, de fato, não trazem contribuições efetivas para sua requalificação, tanto no que se refere aos seus edifícios de interesse de preservação, quanto aos espaços públicos. Programas de requalificação de zonas degradados envolvem a participação de diversos agentes públicos e privados. As operações urbanas que implementaram transformações significativas em centros históricos, como em Barcelona e em Baltimore, tiveram como base planos urbanos. No caso do Recife, a inexistência de um plano de requalificação para esta área permitiu não apenas a viabilidade do empreendimento como também a emergência de argumentos baseados na livre iniciativa privada como a redentora da qualidade de vida pública. Ou seja, a ausência do poder do estado, seja no controle urbano, seja na elaboração de políticas de requalificação, permitiu e vem permitindo a descaracterização do seu mais rico patrimônio.

Uma política que de fato tenha impactos sobre a salvaguarda do patrimônio consideraria empreendimentos que oferecessem uma diversidade de classes sociais e que tivessem no espaço público o meio para maximização de interfaces entre moradores e usuários. Para isso, a municipalidade exerceria o seu papel de gestor dos espaços públicos para permitir o uso indiscriminado de usuários, atendendo ao que estabelece a lei de acessibilidade universal. O foco de novos empreendimentos, portanto, seria na contribuição para a valorização do ambiente urbano e não na estratégia de agregação de valor aos empreendimentos imobiliários pela 
apropriação de aspectos imagéticos a ele relacionados.

Esta premissa estaria calcada na incorporação de atividades pré-existentes e na inclusão de usos adequados ao cotidiano de moradores atuais, como forma de inclusão no processo de requalificação. É evidente que usos inadequados ao sítio histórico, por agressão às peculiaridades históricas, artísticas e arquitetônicas do local, devem ser suprimidos ou adequados. Por este motivo, estabelecer-se-ia o patrimônio tombado como foco nas ações de requalificação, através da ação integrada entre proprietários, financiamento estatal, incentivo municipal e participação da sociedade organizada (comerciantes, comerciários, funcionários públicos), e envolver-se-ia a iniciativa privada em ações de consolidação dos investimentos pela complementaridade de esforços nas áreas de reinvestimento (Smith, 1996), desde que adequados aos propósitos do plano. Para tanto, faz necessário o estudo de novos tipos edilícios para adequar os empreendimentos imobiliários às peculiaridades urbanas e paisagísticas, e que, por outro lado, possam garantir densidades construtivas adequadas ao sucesso do empreendimento. A torre de apartamento é uma solução edilícia consolidada no mercado imobiliário local, mas não é a única capaz de atender às demandas do mercado. Investir em novas soluções arquitetônicas que se adaptem aos diversos padrões urbanos é papel dos agentes do mercado imobiliário, caso contrário, como em um surto epidêmico, as cidades estarão fadadas à infestação de um único tipo edilício.

Em síntese, projetos consistentes de requalificação de áreas degradadas devem ser fundamentados em estudos detalhados sobre as condições de uso e ocupação, e do levantamento das condições de conservação dos imóveis e dos espaços públicos. Devem, ainda, caracterizar a acervo edilício e o arranjo urbano e tomá-los como pressupostos no desenvolvimento dos planos urbanos e de intervenção no patrimônio existente. Estas recomendações são parte das práticas consagradas internacionalmente na requalificação e intervenção em sítios históricos. Nenhum deles foi observado no episódio das Torres Gêmeas do Recife, principalmente aquele que toma a paisagem natural como componente intrínseco da noção de preservação patrimonial. O verdadeiro pioneirismo apresentado pelo empreendedor e defendido pelos articulistas estaria em um empreendimento que promovessem a recuperação do que é característico do Recife e que, historicamente, constituiu seu traço distintivo.

Referências bibliográficas

AMORIM, L.; LOUREIRO, C. Alice's mirror: marketing strategies and the creation of the ideal home . In: FOURTH INTERNATIONAL SPACE SYNTAX SYMPOSIUM, 2003, Londres. Proceedings .... Londres: Space Syntax, 2003, v. 1. p. 22.1-22.16.

BORBA, C.; LOUREIRO, C.; AMORIM, L. Um tesouro para toda a vida ... logo ali!: de como o sonho de morar é construído. In: NUTAU 2002: sustentabilidade, arquitetura e desenho urbano, 2002, São Paulo. Anais ... São Paulo : NUTAU, 2002. p. 313-320.

CHOAY, F., Alegoria do patrimônio. São Paulo: Editora UNESP, 2001.

CRUZ, J. Das torres de São José à torre Eiffel. Diário de Pernambuco. Recife, 30 mar. 2005, Coluna Opinião, Caderno A, p. A3.

FERRAZ, M. A. P. O Recife sob ameaça do atraso. Diário de Pernambuco. Recife, 23 mar. 2005, 
Coluna Opinião, Caderno A, p. A3.

IPHAN. Plano de preservação sítio histórico urbano: termo geral de referência. Brasília: IPHAN, 2003. Disponível em <http://www.iphan.gov.br>.Acesso em: 10 de novembro de 2004.

LAPROVITERA, E. A preservação ameaça a Democracia?. Diário de Pernambuco. Recife, 27 mar. 2005, Coluna Opinião, Caderno A, p. A3.

LOUREIRO, C. ; AMORIM, L. A moradia dos sonhos: onde e como morar. In: XI ENCONTRO NACIONAL DE TECNOLOGIA DO AMBIENTE CONSTRUÍDO, ENTAC 2002, 2002, Foz do Iguaçú. Anais... Foz do Iguaçu: ANTAC, 2002. p. 819-827.

LOUREIRO, C.; AMORIM, L. Dize-me teu nome, tua altura e onde moras e te direi quem és: estratégias de marketing e a criação da casa ideal - parte 1. Arquitexto - Revista Eletrônica, São Paulo. Disponível em: <http://www.vitruvius.com.br/arquitextos/arq000/esp281.asp>. Acesso em: 28 de fev. 2005.

LOUREIRO, C.; AMORIM, Luiz. Dize-me teu nome, tua altura e onde moras e te direi quem és: estratégias de marketing e a criação da casa ideal - parte 2. Arquitexto - Revista Eletrônica, São Paulo. Disponível em: <http://www.vitruvius.com.br/arquitextos/arq000/esp286.asp>. Acesso em: 20 de mar. 2005.

MAIOR, M. S.; SILVA, L. D. (org.) O Recife: quatro séculos de sua paisagem. Recife: FUNDAJ, Editora Massangana, 1992.

MERCADO imobiliário atrai estrangeiros. Jornal do Commercio. Recife, 27 de jan. 2005. disponível em: < http://jc.uol.com.br/jornal/2005/01/27/not_124155.php>. Acesso em: 28 jan. 2005, 2005b.

MP vai à Justiça contra prédios já licenciados. Jornal do Commercio. Recife, 11 de mar. 2005. Disponível em: <http://jc.uol.com.br/jornal/2005/03/11/not_129240.php>. Acesso em: 11 mar. 2005, 2005a.

NASCIMENTO, C. et al. De todos os tipos, preços, tamanhos e ao gosto do freguês: sobre a implantação da habitação econômica privada no recife. In: CLACS'04 - CONSTRUÇÃO SUSTENTÁVEL - I CONFERÊNCIA LATINO-AMERICANA DE CONSTRUÇÃO SUSTENTÁV̧EL, 2004, São Paulo, 2004.

SMITH, N. The new urban frontier: gentrification and the revanchist city. London: Routledge, 1996.

SOUZA, L., AMORIM, e LOUREIRO, C. Morar no moderno: preservando a moradia no centro.In: CLACS'04 - CONSTRUÇÃO SUSTENTÁVEL - I CONFERÊNCIA LATINO-AMERICANA DE CONSTRUÇÃO SUSTENTÁVEL, 2004, São Paulo, 2004.

TRF libera construção de torres. Diário de Pernambuco, Recife, 19 de mai. 2005, Últimas, Caderno A, p. A11.

VASCONCELOS, C. São José atrai novos moradores. Jornal do Commercio. Recife, 31 de jul. 2005. disponível em: <http://jc.uol.com.br/jornal/2005/07/31/not_147159.php. Acesso em: 01 ago. 2005. 